\title{
Production of Recombinant Trichoderma reesei Cellobiohydrolase II in a New Expression System Based on Wickerhamomyces anomalus
}

\author{
Dennis J. Díaz-Rincón, ${ }^{1}$ Ivonne Duque, ${ }^{1}$ Erika Osorio, ${ }^{1}$ \\ Alexander Rodríguez-López, ${ }^{1,2}$ Angela Espejo-Mojica, ${ }^{1}$ Claudia M. Parra-Giraldo, ${ }^{3}$ \\ Raúl A. Poutou-Piñales, ${ }^{4}$ Carlos J. Alméciga-Díaz, ${ }^{1}$ and Balkys Quevedo-Hidalgo ${ }^{4}$ \\ ${ }^{1}$ Institute for the Study of Inborn Errors of Metabolism, Facultad de Ciencias, Pontificia Universidad Javeriana, Bogotá, Colombia \\ ${ }^{2}$ Departamento de Química, Facultad de Ciencias, Pontificia Universidad Javeriana, Bogotá, Colombia \\ ${ }^{3}$ Unidad de Proteómica y Micosis Humanas, Grupo de Enfermedades Infecciosas, Departamento de Microbiología, \\ Facultad de Ciencias, Pontificia Universidad Javeriana, Bogotá, Colombia \\ ${ }^{4}$ Grupo de Biotecnología Ambiental e Industrial (GBAI), Departamento de Microbiología, Facultad de Ciencias, \\ Pontificia Universidad Javeriana, Bogotá, Colombia
}

Correspondence should be addressed to Carlos J. Alméciga-Díaz; cjalmeciga@javeriana.edu.co and Balkys Quevedo-Hidalgo; bquevedo@javeriana.edu.co

Received 12 May 2017; Revised 19 July 2017; Accepted 2 August 2017; Published 30 August 2017

Academic Editor: Sunney I. Chan

Copyright (C) 2017 Dennis J. Díaz-Rincón et al. This is an open access article distributed under the Creative Commons Attribution License, which permits unrestricted use, distribution, and reproduction in any medium, provided the original work is properly cited.

Cellulase is a family of at least three groups of enzymes that participate in the sequential hydrolysis of cellulose. Recombinant expression of cellulases might allow reducing their production times and increasing the low proteins concentrations obtained with filamentous fungi. In this study, we describe the production of Trichoderma reesei cellobiohydrolase II (CBHII) in a native strain of Wickerhamomyces anomalus. Recombinant CBHII was expressed in W. anomalus 54-A reaching enzyme activity values of up to $14.5 \mathrm{U} \mathrm{L}^{-1}$. The enzyme extract showed optimum $\mathrm{pH}$ and temperature of 5.0-6.0 and 40 ${ }^{\circ}$, respectively. Enzyme kinetic parameters ( $K_{M}$ of $2.73 \mathrm{mM}$ and $V \max$ of $23.1 \mu \mathrm{M} \mathrm{min}^{-1}$ ) were between the ranges of values reported for other CBHII enzymes. Finally, the results showed that an enzymatic extract of $W$. anomalus 54-A carrying the recombinant $T$. reesei CBHII allows production of reducing sugars similar to that of a crude extract from cellulolytic fungi. These results show the first report on the use of $W$. anomalus as a host to produce recombinant proteins. In addition, recombinant $T$. reesei CBHII enzyme could potentially be used in the degradation of lignocellulosic residues to produce bioethanol, based on its $\mathrm{pH}$ and temperature activity profile.

\section{Introduction}

Cellulases are enzymes from the glycoside hydrolase family (EC 3.2.1.-) that are expressed by a broad spectrum of bacteria and fungi strains $[1,2]$. Among these microorganisms, whiteand brown-rot fungi are considered the major producers of cellulases, including Trichoderma sp., Aspergillus sp., Schizophyllum commune, and Volvariella volvacea $[1,2]$. Cellulase is a family of at least three groups of enzymes: endo- $(1,4)-\beta$ $D$-glucanase (EC 3.2.1.4, EG), exo-(1,4)- $\beta$-D-glucanase (EC 3.2.1.91, CBH), and $\beta$-glucosidases (EC 3.2.1.21, BG) [3]. These enzymes act sequentially on the cellulose hydrolysis: (1) EG randomly attacks on $\mathrm{O}$-glycosidic bonds resulting in glucan chains of different lengths, (2) $\mathrm{CBH}$ acts on glucan chains ends to release $\beta$-cellobiose, and (3) BG hydrolyzes the $\beta$ cellobiose to produce glucose [3].

Trichoderma reese $i$ is one of the most important cellulases producing filamentous fungi, since it contains the core enzymes necessary for the complete hydrolysis of lignocellulose material [4]. Among these enzymes, cellobiohydrolases have been shown to be one of the most important components within this process [4]. Enzymes involved in hydrolysis 
of cellulose polymer molecules have been recombinantly expressed [5], which might allow reducing the production times and increasing the low proteins concentrations obtained with filamentous fungi. Recombinant expression might also facilitate the scaling up of the enzyme production, as well as the implementation of Simultaneous Saccharification and Fermentation (SSF) and Separate Hydrolysis and Fermentation (SHF) processes. Saccharomyces cerevisiae has been used for the production of recombinant $\mathrm{CBH}$ from Phanerochaete chrysosporium [6] and Talaromyces emersonii [7], while T. reesei CBHII has been expressed in S. cerevisiae $[8,9]$, P. pastoris $[10,11]$, and Y. lipolytica [11].

Conventional microbial systems (e.g., E. coli, S. cerevisiae, and $P$. pastoris) have allowed the production of a long list of recombinant proteins [12]. However, there is a growing interest in the identification of new hosts that allow the production of high-quality or cost-efficient recombinant proteins [13]. Recently, a native strain of Wickerhamomyces anomalus was isolated from sugar cane bagasse at Puerto López, Meta, Colombia (unpublished results). W. anomalus is a yeast that has been isolated from different sources [14], and its reported applications include food biopreservation, bioremediation, and production of phytases and biofuels $[14,15]$. However, to the best of our knowledge, there are no reports showing its use as host to produce recombinant proteins.

In this paper, we describe the production of recombinant cellobiohydrolase II (CBHII, EC 3.2.1.91) from $T$. reesei using the native strain $W$. anomalus 54-A. Furthermore, the effects of $\mathrm{pH}$ and temperature on enzyme activity were characterized, as well as the kinetic properties of the enzyme and its application on the hydrolysis of a lignocellulose material. Overall, the results showed the potential of $W$. anomalus 54A as host to produce recombinant proteins and showed that recombinant $T$. reesei CBHII has similar characteristics to those reported for the wild-type enzyme.

\section{Materials and Methods}

2.1. Microorganism, Culture Media, and Vectors. W. anomalus 54-A was previously isolated from sugar cane bagasse at Puerto López, Meta, Colombia. Initially, the microorganism was identified by carbon assimilation profile using the API 20C AUX kit (bioMérieux, Marcy l'Etoile, France). Further microorganism identification was done by amplification of internal transcribed spacer (ITS), using the primers ITS1 $5^{\prime}$-TCCGTAGGTGAACCTGCGG-3 ${ }^{\prime}$ and ITS 4 $5^{\prime}$-TCCTCCGCTTATTGATATGC- $3^{\prime}$ and $P f u$ DNA polymerase (Thermo Fisher Scientific Inc., San Jose, CA, US), under manufacturer instructions. Identity of $W$. anomalus 54 A was finally confirmed by MALDI-TOF analysis (Unidad de Investigación en Proteómica y Micosis Humana, Pontificia Universidad Javeriana).

Plasmid pKS2-ST (Dualsystems Biotech, Schlieren, Switzerland) was used as expression vector. In this vector, protein expression is regulated by the alcohol dehydrogenase II promoter (EC 1.1.1.1, ADH2), while the secretion signal of the Saccharomyces cerevisiae invertase SUC2 mediates the secretion of the recombinant protein. Escherichia coli DH5 was used for cloning purposes, which was cultured in Luria-Bertani (LB) medium supplemented with $100 \mathrm{mg} \mathrm{mL}^{-1}$ ampicillin. Yeast cultures were performed in YPD supplemented with $500 \mathrm{mg} \mathrm{mL}^{-1}$ geneticin for the selection of clones and $60 \mathrm{mg} \mathrm{mL}^{-1}$ for protein expression cultures.

2.2. Expression Vector and Recombinant Strains. Cellobiohydrolase II gene (cbhII) from T. reesei (GenBank Number GU724763.1) was previously codon-optimized for its expression in S. cerevisiae by GeneArt ${ }^{\mathrm{TM}}$ (Thermo Fisher Scientific Inc.) (unpublished data). The sequence encoding for the CBHII signal peptide was identified by using SignalP [16] and removed from the gene sequence. Comparison of the codon usage tables of $S$. cerevisiae and $W$. anomalus showed a similar profile between both microorganisms (Supplementary Figure 1 in Supplementary Material available online at https://doi.org/10.1155/2017/6980565) Two codons (CGC and CGG), which encode $\operatorname{Arg}$ (14 residues, $3 \%$, in CBHII) showed significant differences between both microorganisms. Nevertheless, the other two Arg codons have a comparable usage between $S$. cerevisiae and $W$. anomalus. In this sense, this codon optimized sequence was used for the CBHII expression in W. anomalus 54-A. Codon optimized cbhII gene was inserted downstream of the SUC2 secretion signal in the vector pKS2-ST, to produce pKS2-ST::CBHII (Supplementary Figure 2). The pKS2-ST::CBHII vector was used to transform competent cells of $W$. anomalus 54-A by electroporation, using the Gene Pulser electroporation system Xcell ${ }^{\mathrm{TM}}$ (BioRad Laboratories) at $1400 \mathrm{~V}$ and $200 \Omega$. The W. anomalus 54-A clones were selected in YPD medium supplemented with $500 \mathrm{mg} \mathrm{mL}^{-1}$ geneticin. Clones were confirmed by PCR using the primers $5^{\prime}$-GAGGAGAGCATAGAAATGGGG-3' and $5^{\prime}$-CAGCAGTAGCCATAGCACCA- ${ }^{\prime}$, which amplify a fragment from cbhII gene. The PCR-positive clones were evaluated at $55 \mathrm{~mL}$ scale, according to vector pKS2-ST manufacturer's instructions (Dualsystems Biotech). Briefly, each clone was incubated for $10 \mathrm{~h}$ in $10 \mathrm{~mL}$ YPD, after which $15 \mathrm{~mL}$ of fresh YPD medium was added. After $14 \mathrm{~h}$ incubation, $30 \mathrm{~mL}$ of fresh YPD medium was added to reach a final culture volume of $55 \mathrm{~mL}$. After $6 \mathrm{~h}$ of incubation, it was expected that the glucose was exhausted, and this time was considered as the beginning of the induction phase. $1 \mathrm{~mL}$ aliquots were taken every $24 \mathrm{~h}$ for $96 \mathrm{~h}$ to measure extracellular enzyme activity and cell density. All the assays were performed in triplicate at $28^{\circ} \mathrm{C}$ and $180 \mathrm{rpm}$. Residual glucose quantitation was carried out by DNS method [17]. Crude extracellular fractions of the clone with the highest enzyme activity were loaded and processed by SDS-PAGE.

2.3. Evaluation of Carbon Sources. The clone that showed the highest enzyme activity was used to evaluate the effect of carbon source (i.e., glucose and glycerol) on the enzyme production. Cultures were carried out in $2 \%(\mathrm{w} / \mathrm{v})$ tryptone and $1 \%(\mathrm{w} / \mathrm{v})$ yeast extract, supplemented with glycerol and glucose in different concentrations: $2 \%(\mathrm{w} / \mathrm{v})$ glucose, $1 \%(\mathrm{w} / \mathrm{v})$ glucose, $1 \%(\mathrm{w} / \mathrm{v})$ glycerol, $2 \%(\mathrm{w} / \mathrm{v})$ glucose, $1 \%$ $(\mathrm{w} / \mathrm{v})$ glycerol, and $2 \%(\mathrm{w} / \mathrm{v})$ glycerol. All cultures were supplemented with $60 \mathrm{mg} \mathrm{mL}^{-1}$ geneticin. 
2.4. Culture at 2.4 L Scale. The W. anomalus 54-A clone that showed the highest CBHII activity at $55 \mathrm{~mL}$ scale was scaled up to $2.4 \mathrm{~L}$ in a $3.7 \mathrm{~L}$ Bioengineering KFL2000 bioreactor. Cultures were done in modified YPD medium [2\% $(\mathrm{w} / \mathrm{v})$ tryptone, $1 \%(\mathrm{w} / \mathrm{v})$ yeast extract, $1 \%(\mathrm{w} / \mathrm{v})$ glucose, and $1 \%$ $(\mathrm{w} / \mathrm{v})$ glycerol] supplemented with $60 \mathrm{mg} \mathrm{mL}^{-1}$ geneticin. Briefly, $2 \mathrm{~mL}$ from the cell bank was inoculated into $18 \mathrm{~mL}$ of culture medium and incubated for $24 \mathrm{~h}$ at $28^{\circ} \mathrm{C}$ and $180 \mathrm{rpm}$. The preinoculum was used to inoculate $180 \mathrm{~mL}$ of fresh culture medium and incubated for $24 \mathrm{~h}$ at $28^{\circ} \mathrm{C}$ and $180 \mathrm{rpm}$. Finally, the inoculum was used to inoculate $1000 \mathrm{~mL}$ of fresh culture medium at the bioreactor. After $15 \mathrm{~h}$ culture, $1200 \mathrm{~mL}$ of fresh medium was added to reach a final volume of $2.4 \mathrm{~L}$ and cultured during additional $96 \mathrm{~h}$ at $28^{\circ} \mathrm{C}, 400$ to $800 \mathrm{rpm}$, and $\mathrm{pH} 6.0$.

2.5. Cellobiohydrolase Activity Assay. The CBHII activity was carried out as previously described $[18,19]$, using $5 \mathrm{mM}$ p-nitrophenyl $\beta$-D-cellobioside (pNPC, Sigma-Aldrich) in sodium acetate buffer $50 \mathrm{mM}, \mathrm{pH}$ 5.0. One enzyme unit was defined as the amount of enzyme releasing $1 \mu \mathrm{mol}$ of $\mathrm{p}$ nitrophenol per min, and the activity was expressed as $\mathrm{UL}^{-1}$.

2.6. Characterization of Recombinant CBHII. The CBHII enzyme extract was evaluated at different $\mathrm{pH}$ and temperature conditions, using pNPC. To evaluate the effect of $\mathrm{pH}$ and temperature on enzyme activity, the enzyme activity assay was performed at 3.0, 4.0, 5.0, 6.0, 7.0, and $8.0 \pm$ 0.2 and at $30,40,50,60$, and $70^{\circ} \mathrm{C}$ for $1 \mathrm{~h}$. The reactions were stopped and read as described above. Apparent kinetic parameters $\left(K_{M}\right.$ and $\left.V \max \right)$ were estimated for the crude extract by using pNPC between 0 and $6.5 \mathrm{mM}$ and fitting the experimental data to a Michaelis-Menten model using the software GraphPad PRISM 6.0.

2.7. Chrysanthemum Wastes Degradation Assay. The effect of recombinant CBHII on cellulose hydrolysis was evaluated by using Chrysanthemum wastes, as previously described $[18,19]$, with modifications. Chrysanthemum wastes were autoclaved at $121^{\circ} \mathrm{C}$ for $15 \mathrm{~min}$. Experiments were performed in substrate submerged cultures carried out in $100 \mathrm{~mL}$ flasks in a rotatory shaker at $150 \mathrm{rpm}$ and $30^{\circ} \mathrm{C}$, for 20 days. Flasks contained 1\% Chrysanthemum wastes in $40 \mathrm{~mL}$ of the following enzyme crude extracts: (1) cellulolytic and hemicellulolytic extract from a Penicillium sp. culture (hereafter CeHem extract), (2) concentrated recombinant CBHII extract from $W$. anomalus 54-A (hereafter rCBHII), and (3) a 1:1 CeHem : rCBHII extracts mixture. Control culture was carried out by using $40 \mathrm{~mL}$ of distilled water. All cultures were carried out with $10 \mathrm{mM}$ sodium azide, $0.1 \%$ tween 80 , and $\mathrm{pH}$ 5.0. The response variable was the concentration of reducing sugars as measured by DNS method [17]. Results are reported as $\mathrm{g} \mathrm{L}^{-1}$ of reducing sugars after subtraction of the results obtained with the control cultures, and normalized by the initial unis of CBHII present in each extract. Production of Ce-Hem extract was carried out by using a Penicillium sp. strain (Collection of Microorganisms of Pontificia Universidad Javeriana). For this purpose, $20 \mathrm{~mL}$ of a $10^{6}$ conidia $\mathrm{mL}^{-1}$ suspension was inoculated in $200 \mathrm{~mL}$ of a rice straw medium without nitrogen source and incubated for 8 days at $28^{\circ} \mathrm{C}$ and $120 \mathrm{rpm}$. The crude extract was obtained by centrifugation and sequential filtrations through Whatman paper Number 42 and 0.45 and $0.22 \mu \mathrm{m}$ polyether sulphone membranes (Pall Corp, Port Washington, NY, USA). Concentrated recombinant CBHII extract from $W$. anomalus $54-\mathrm{A}$ was produced by using a $2.4 \mathrm{~L}$ culture of the $W$. anomalus $54-\mathrm{A}$ Celo-3.2 clone, as described above. Culture medium was centrifuged at $8000 \mathrm{~g}$ and filtered sequentially through Whatman paper Number 42 and 0.45 and $0.22 \mu \mathrm{m}$ polyether sulphone membranes (Pall Corp). Permeate was ultrafiltered through a $30 \mathrm{kDa}$ cut-off membrane (Millipore, Billerica, MA, USA), until reaching a final volume of $20 \mathrm{~mL}$. CBHII activity in both extracts was assayed as described above. The $\beta$-glucosidase (BG) activity in both extracts was assayed using $5 \mathrm{mM} 4$-nitrophenyl $\beta$ D-glucuronide (Sigma-Aldrich) as previously described [18, 19]. One BG unit was defined as the amount of enzyme releasing $1 \mu \mathrm{mol}$ of $\mathrm{p}$-nitrophenol per min, and the activity was expressed as $\mathrm{UL}^{-1}$. The endoglucanase (EG) activity in both extracts was assayed using 2\% carboxymethylcellulose (Sigma-Aldrich) [18, 19] and the DNS method for quantitation of reducing sugars [17]. One EG unit was defined as the amount of enzyme releasing $1 \mu \mathrm{mol}$ of reducing sugars, equivalent to glucose, per min [20], and the activity was expressed as $\mathrm{UL}^{-1}$.

2.8. Statistical Analysis. Differences between groups were tested for statistical significance by using one-way ANOVA. An error level of 5\% $(p<0.05)$ was considered significant. All analyses were performed using the software GraphPad PRISM 6.0.

\section{Results and Discussion}

3.1. Production of Recombinant CBHII in W. anomalus 54-A. In this study, we evaluated the production of the recombinant CBHII in the native yeast strain 54-A, previously isolated from sugar cane bagasse from Puerto López, Meta, Colombia. This strain showed a carbon assimilation profile (API 20C AUX, bioMérieux) different from that observed for $S$. cerevisiae strains, and it was identified as Pichia anomala (recently renamed as Wickerhamomyces anomalus [21]) with a 94.5\% ID and 0,25 $T$ value. Identity of this strain was further confirmed as $W$. anomalus through ITS amplification (GenBank accession number KX676490, Supplementary Figure 3) and MALDI-TOF analysis (Supplementary Figure 4). W. anomalus is a yeast that have been isolated from different sources, such as food- and feed-related systems, insects, and human clinical samples. This yeast has a wide robustness to environmental stresses conditions like extreme $\mathrm{pH}$ or low water activity [14]. Biotechnological applications of $W$. anomalus strains include biopreservation agent due to antimicrobial activity against variety of microorganisms in fruits and cereals and production of enzymes (e.g., phytases), biofuels, and bioremediation [14, 15]. However, to the best of our knowledge, there are no reports of the use of this yeast as a host to produce recombinant proteins. 

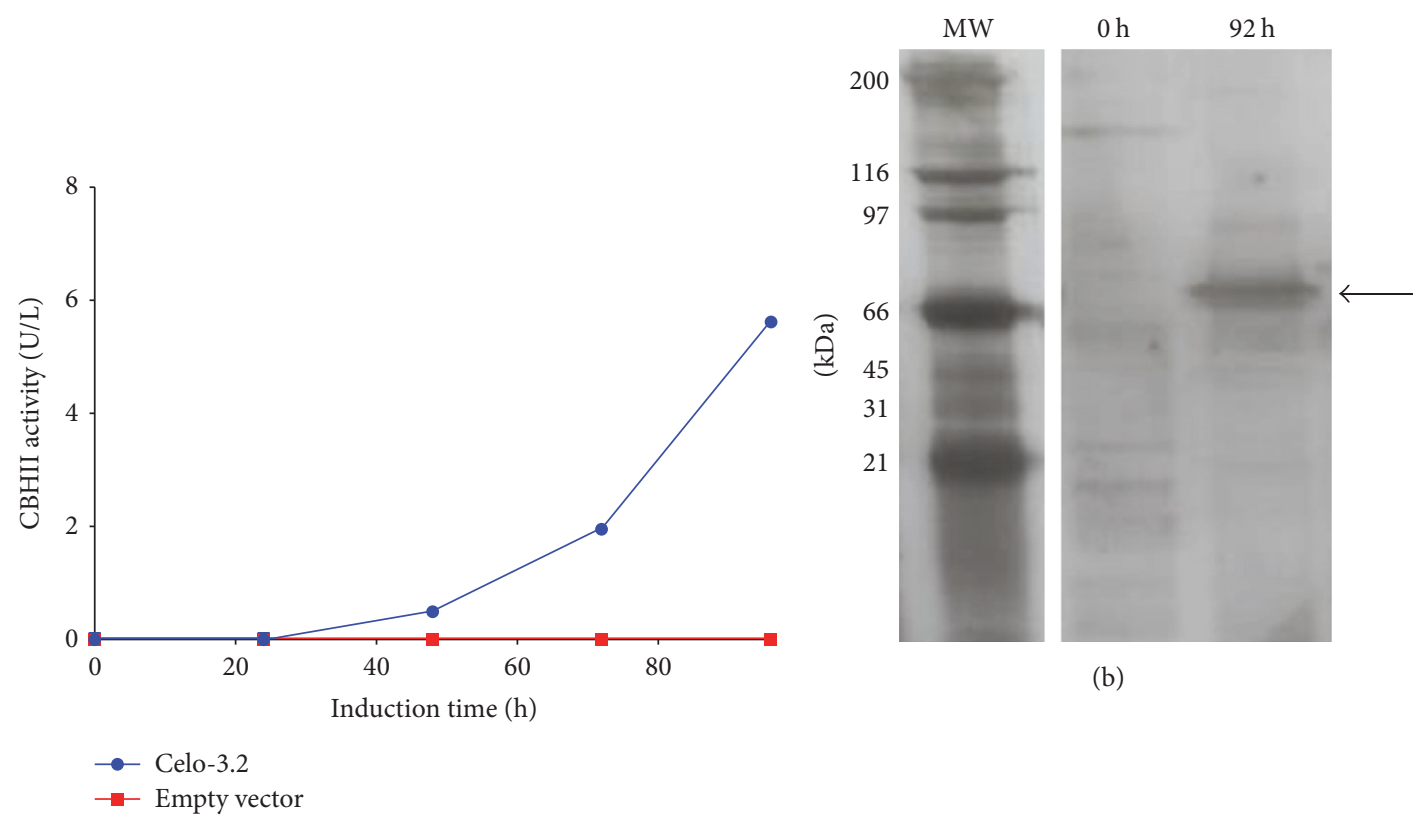

(b)

(a)

Figure 1: Recombinant T. reesei CBHII produced in W. anomalus 54-A. (a) PCR-positive clones of W. anomalus 54-A were evaluated at $55 \mathrm{~mL}$ scale and the activity of recombinant $T$. reesei CBHII was assayed in the extracellular fraction. Among the four PCR-positive clones, only $W$. anomalus 54-A Celo 3.2 clone showed CBHII activity. No activity was observed in W. anomalus 54-A transfected with the empty vector. Each clone was evaluated in triplicate. (b) Crude extracellular extracts from W. anomalus 54-A Celo 3.2 at 0 and $92 \mathrm{~h}$ were evaluated by SDS-PAGE, followed by silver staining. The arrow indicates the recombinant CBHII.

Four clones were obtained after transformation of $W$. anomalus 54-A with the vector pKS2-ST::CBHII (Celo-2.2, Celo-3.2, Celo-4.2, and Celo-5.1), which were confirmed by $\mathrm{PCR}$. The $A D H 2$ gene promoter is repressed in the presence of glucose, since this metabolite inhibits the expression of the alcohol dehydrogenase regulator protein (Adr1) that is an activator of the $A D H 2$ gene. On the other hand, under glucose depletion conditions, the expression of Adr1 is increased leading to the induction of the $A D H 2$ gene [22]. In this sense, we first determined the residual glucose during the culture of W. anomalus 54-A pKS2-ST::CBHII clones, to establish the beginning of the induction phase. We observed, for all the evaluated clones, that, at the final culture step, the glucose was consumed within the first $6 \mathrm{~h}$ of incubation (Supplementary Figure 5). In this sense, this point was considered as the beginning of the induction phase, which agrees with previous reports of the production of recombinant proteins in yeast under the control of the $A D H 2$ gene promoter [22, 23]. Under these culture conditions, extracellular CBHII activity was only detected in W. anomalus 54-A Celo-3.2 clone, reaching a final enzyme activity of $5.7 \mathrm{UL}^{-1}$ after $96 \mathrm{~h}$ of induction (Figure 1(a)). As expected, CBHII activity was not detected in $W$. anomalus 54-A transfected with the empty vector.

As was mentioned above, $T$. reesei CBHII has been expressed in S. cerevisiae [8, 9], $P$. pastoris $[10,11]$, and $Y$. lipolytica [11]. Recombinant CBHII produced in S. cerevisiae showed an activity of 25 S.I. $\mathrm{U} \mathrm{mL}^{-1}$ using barely $\beta$-glucan as substrate [8], while recombinant CBHII produced in $P$. pastoris GS115 showed an enzyme activity of $5.84 \mathrm{U} \mathrm{mL}^{-1}$ at $96 \mathrm{~h}$ using microcrystalline cellulose PH101 as substrate [10]. In P. pastoris X-33 and Y. lipolytica POld, extracellular recombinant CBHII activities were 0.25 and $0.36 \mathrm{U} \mathrm{mL}^{-1}$, respectively, using phosphoric acid swollen cellulose (PASC) prepared from Avicel PH-101 as substrate [11]. The differences in promoters, secretion signals, hosts, and enzyme activity substrates limit the comparison between these results and those obtained for recombinant CBHII produced in $W$. anomalus 54-A. However, a crude culture broth from Penicillium sp. containing wild-type cellulase and hemicellulase enzymes (see Chrysanthemum Wastes Degradation Assay) showed a CBHII activity of $8.5 \mathrm{U} \mathrm{L}^{-1}$ using the pNPC substrate, which was similar to that observed for the recombinant CBHII produced in W. anomalus 54-A. Nevertheless, these results are lower than those observed for erlenmeyer flask cultures of Pleurotus ostreatus, which showed an activity of $445.3 \pm 27.6 \mathrm{U} \mathrm{L}^{-1}$ using the pNPC substrate $[18,19]$.

SDS-PAGE analysis of extracellular fraction of W. anomalus 54-A Celo-3.2 showed that recombinant CBHII has an apparent molecular weight of about $66 \mathrm{kDa}$ (Figure 1(b)). This recombinant CBHII is higher than the wild-type enzyme produced by $T$. reesei $(50-58 \mathrm{kDa})$ [24]. However, recombinant CBHII produced in $W$. anomalus 54- $A$ has a molecular weight similar to that reported for a CBHII produced in $P$. pastoris X33 and Y. lipolytica POld ( 63-65 kDa) [11] but higher than that reported for the enzyme produced in $P$. pastoris GS115 ( $58 \mathrm{kDa})$ [10]. Differences in the molecular weight between wild-type and the recombinant counterpart could be associated with the hypermannosylation observed 


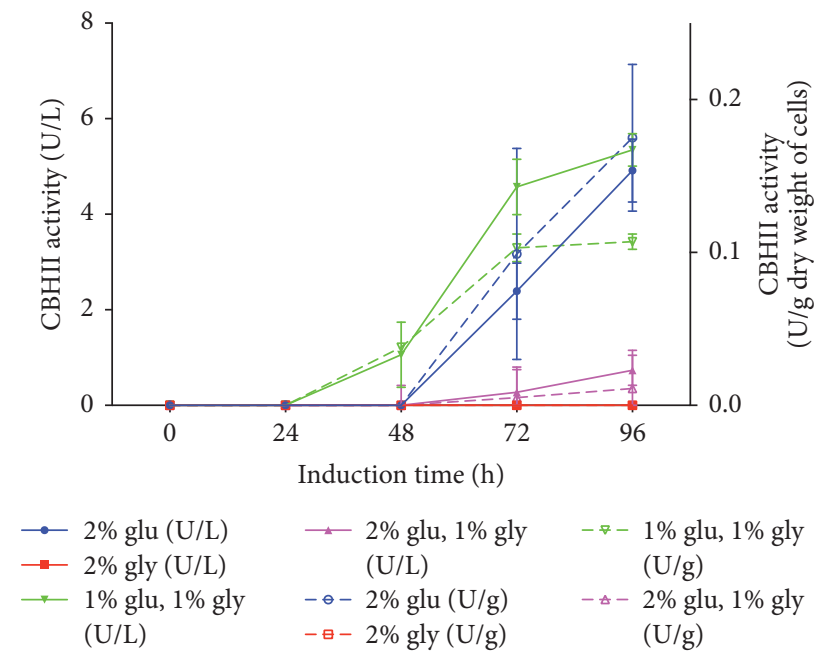

FIGURE 2: Effect of the carbon source on the production of recombinant $T$. reesei $\mathrm{CBHII}$. Production of recombinant $\mathrm{CBHII}$ was carried out at $55 \mathrm{~mL}$ with $2 \%(\mathrm{w} / \mathrm{v})$ glucose (circle), $2 \%$ (w/v) glycerol (square), $2 \%(\mathrm{w} / \mathrm{v})$ glucose, $1 \%(\mathrm{w} / \mathrm{v})$ glycerol (up triangle), and $1 \%$ $(\mathrm{w} / \mathrm{v})$ glucose, $1 \%(\mathrm{w} / \mathrm{v})$ glycerol (down triangle). Enzyme activity is reported as $\mathrm{UL}^{-1}$ (continuous line) and $\mathrm{Ug}^{-1}$ dry weight of cells (dashed line). Each experiment was done in triplicate.

in yeast, while the differences in the molecular weight among the recombinant CBHII could be associated with several factors of the culture conditions that affect the expression of glycosyltransferases [25].

3.2. Evaluation of Carbon Sources. To improve the production of recombinant CBHII, two glucose and glycerol concentrations were evaluated. First, 1\% w/v glucose was evaluated, which is lower than the concentration suggested by the vector manufacturer $(2 \% \mathrm{w} / \mathrm{v})$. We hypothesize that $1 \% \mathrm{w} / \mathrm{v}$ glucose would be depleted faster than $2 \% \mathrm{w} / \mathrm{v}$, allowing a reduction in the induction time and a longer and higher enzyme production [22]. In addition, glycerol, alone or in combination with glucose, was also evaluated as a carbon source, since it was expected that glycerol would be used for yeast growth after depletion of glucose, increasing the production of the recombinant enzyme.

Figure 2 shows the results of volumetric activity $\left(\mathrm{UL}^{-1}\right)$ and enzyme activity normalized by biomass $\left(\mathrm{U} \mathrm{g}^{-1}\right.$ dry weight of cells). A similar activity profile was observed between volumetric and normalized enzyme activities, suggesting that the production of recombinant $\mathrm{CBHII}$ was associated with yeast growth. In fact, the profile of recombinant CBHII production was similar to that previously reported for the $\mathrm{ADH} 2$ promoter, with a complete induction in the late stationary phase ( $>36 \mathrm{~h}$ culture) [22]. The results showed that in $2 \%(\mathrm{w} / \mathrm{v})$ glycerol cultures no CBHII activity was detected, suggesting that the glycerol was used for cell growth or that the $\mathrm{ADH} 2$ promoter needs to sense the glucose depletion to induce the gene expression. On the other hand, lower CBHII activity was observed at $2 \%(\mathrm{w} / \mathrm{v})$ glucose, $1 \%(\mathrm{w} / \mathrm{v})$ glycerol, cultures compared to that obtained with $2 \%(\mathrm{w} / \mathrm{v})$ glucose $(p<0.001)$. Finally, the highest CBHII activity was observed

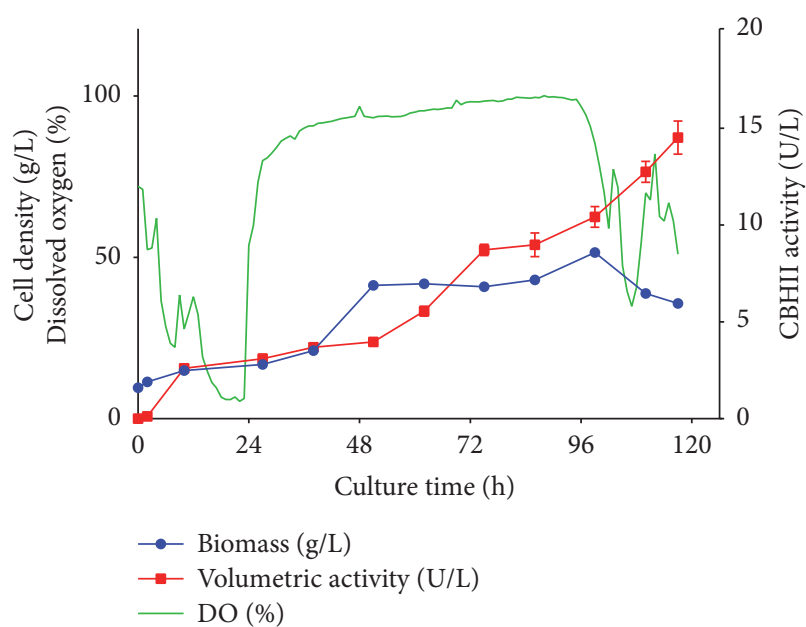

Figure 3: Production of recombinant T. reesei CBHII in W. anomalus 54-A at $2.4 \mathrm{~L}$ scale. Recombinant $T$. reesei $\mathrm{CBHII}$ was produced at $2.4 \mathrm{~L}$ with $1 \%(\mathrm{w} / \mathrm{v})$ glucose and $1 \%(\mathrm{w} / \mathrm{v})$ glycerol. Production was followed by $117 \mathrm{~h}$ after the final feeding step. Dissolved oxygen (\%), cell density $\left(\mathrm{gL}^{-1}\right)$, and extracellular enzyme activity $\left(\mathrm{U} \mathrm{L}^{-1}\right)$ are reported.

at $1 \%(\mathrm{w} / \mathrm{v})$ glucose, $1 \%(\mathrm{w} / \mathrm{v})$ glycerol, although this was not statistically different regarding the levels obtained with $2 \%(\mathrm{w} / \mathrm{v})$ glucose $(p>0.05)$. However, $1 \%(\mathrm{w} / \mathrm{v})$ glucose, $1 \%$ $(w / v)$ glycerol, allowed an earlier detection of the enzyme activity than that observed with $2 \%(\mathrm{w} / \mathrm{v})$ glucose. In this sense, $1 \%(\mathrm{w} / \mathrm{v})$ glucose, $1 \%(\mathrm{w} / \mathrm{v})$ glycerol, was selected to produce recombinant $\mathrm{CBHII}$ at $2.4 \mathrm{~L}$ scale. The reasons of the effect of glycerol on CBHII activity are unknown, and further investigations should be carried out to clarify this aspect. Nevertheless, it is important to mention that there is a wide variation among yeasts, and even strains, regarding glycerol metabolism (i.e., uptake and catabolism) [26]. Although the metabolic pathways and the uptake and regulation (e.g., catabolic repression) process have been widely described for $S$. cerevisiae, limited information is available for other yeasts [26]. In this sense, the effect of glycerol on the changes of enzyme activity levels might be associated with the specific glycerol metabolism of W. anomalus 54-A.

3.3. Production of Recombinant CBHII at 2.4L Scale. The production of recombinant CBHII enzyme at $2.4 \mathrm{~L}$ scale was carried out for $117 \mathrm{~h}$ after the final feeding step (see Materials and Methods). Figure 3 shows the behavior of dissolved oxygen (DO) during the production of recombinant CBHII at bioreactor scale, which could be associated with the consumption of the carbon sources. The CBHII activity was detected from the first $2 \mathrm{~h}$ of culture $(0.12 \pm$ $\left.0.08 \mathrm{U} \mathrm{L}^{-1}\right)$. This activity significantly increased after $10 \mathrm{~h}(2.6$ $\pm 0.09 \mathrm{UL}^{-1}$ ) and continuously kept increasing to reach a final enzyme activity of $14.5 \pm 0.86 \mathrm{UL}^{-1}$, which was 2.7 fold higher than that observed at $55 \mathrm{~mL}$ scale. These results might suggest that, under controlled culture conditions, the strict repression of the $\mathrm{ADH} 2$ promoter might be affected 


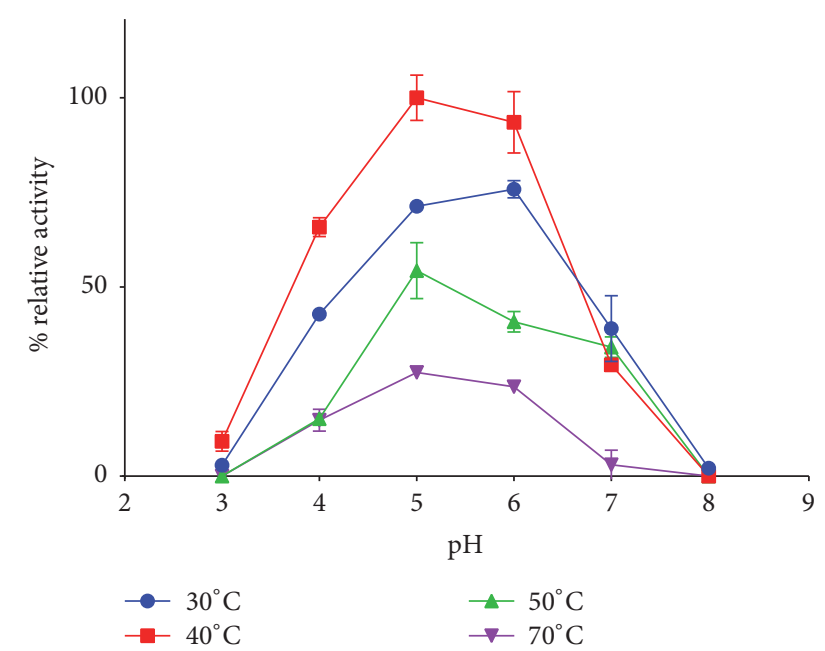

FIGURE 4: Effect of temperature and $\mathrm{pH}$ on reaction of recombinant $T$. reesei $\mathrm{CBHII}$. The enzyme activity of recombinant $T$. reesei $\mathrm{CBHII}$ produced in $W$. anomalus 54-A was evaluated at different $\mathrm{pH}$ and temperatures reactions condition. Each experiment was carried out in triplicate. Activity is reported as \% Relative Activity as compared with the highest activity obtained in the experiment $\left(40^{\circ} \mathrm{C}, \mathrm{pH} 5\right)$.

allowing the expression of the recombinant protein even in the presence of residual glucose.

3.4. Characterization of $C B H$ Recombinant Extract. The effect of temperature and $\mathrm{pH}$ on the enzyme activity of the recombinant CBHII produced in W. anomalus 54-A was evaluated. In this work, crude extract rather than the purified recombinant CBHII was used for characterization, since this crude extract would be used in the production of bioethanol by the degradation of Chrysanthemum residues [19]. As observed in Figure 4, optimum reaction temperature for recombinant CBHII crude extract was $40^{\circ} \mathrm{C}(p<0.001)$, while the highest enzyme activities were observed at $\mathrm{pH} 5.0$ and $6.0 \pm 0.2$ at all evaluated temperatures ( $p<0.001)$. On the other hand, at $\mathrm{pH} 3.0$ and $8.0 \pm 0.2$, a marked decrease in the enzymatic activity was observed regardless of the reaction temperature.

Using microcrystalline cellulose PH101 as substrate, recombinant CBHII produced in $P$. pastoris showed an optimum reaction $\mathrm{pH}$ and temperature of $5.0 \pm 0.2$ and $50^{\circ} \mathrm{C}$, respectively. In addition, this recombinant enzyme showed a significant loss of activity at $\mathrm{pH}$ of 3.0, 7.0, and 8.0 and at $30^{\circ} \mathrm{C}$ and temperatures above $65^{\circ} \mathrm{C}$ [10]. Recombinant CBHII enzyme produced in $P$. pastoris and Y. lipolytica showed an optimum $\mathrm{pH}$ between 5.0 and 6.0 and at a temperature of $60^{\circ} \mathrm{C}$. Recombinant CBHII produced in P. pastoris and $Y$. lipolytica also showed rapid inactivation at $\mathrm{pH}$ and temperatures above 7.0 and $60^{\circ} \mathrm{C}$, respectively, while at temperatures below $40^{\circ} \mathrm{C}$, an $80 \%$ loss in the enzyme activity was observed [11]. In this sense, recombinant T. reesei CBHII produced in $W$. anomalus 54-A has a reaction $\mathrm{pH}$ profile similar to that reported for recombinant CBHII enzymes expressed in other yeast. Nevertheless, it seems that the optimum temperature of reaction differs among the recombinant CBHII enzymes, which might be associated with the substrate used for the enzyme activity assay or the posttranslational modifications carried out for each host. It is noteworthy that recombinant CBHII produced in $W$. anomalus $54-\mathrm{A}$ only showed $30 \%$ reduction in enzyme activity at $30^{\circ} \mathrm{C}$. Functionality at $30^{\circ} \mathrm{C}$ might allow the use of this enzyme in SSF processes for the production of bioethanol, since this temperature is also the optimum growth temperature for S. cerevisiae that is the preferable microorganism used during the fermentation stage of bioethanol production [27].

Kinetic parameters for the crude extract were estimated using pNPC as substrate (Supplementary Figure 6). Recombinant $T$. reesei $\mathrm{CBHII}$ produced in $W$. anomalus $54-\mathrm{A}$ showed $K_{M}$ and $V \max$ of $2.73 \mathrm{mM}$ (est. error 0.26 ) and $23.1 \mu \mathrm{M} \mathrm{min}^{-1}$ (est. error 0.89), respectively. This $K_{M}$ value agrees with those reported for wild-type CBHII enzymes (EC 3.2.1.91) isolated from different microorganisms, which vary between 0.1 and $3.1 \mathrm{mM}$, depending on the source of the enzyme [28]. In the case of $T$. reesei CBHII enzymes there are no reports of kinetic parameters using pNPC substrate. Nevertheless, a wide variation in $K_{M}$ values is observed (i.e., between 0.041 and $380 \mathrm{mM}$ ), depending on the substrate used for this estimation [28].

3.5. Chrysanthemum Wastes Degradation Assay. To evaluate the effect of recombinant CBHII on cellulose hydrolysis, Chrysanthemum wastes degradation assay was performed using three enzyme extracts: (1) a crude culture broth from Penicillium sp. containing wild-type cellulase and hemicellulase enzymes (Ce-Hem extract), (2) a concentrated recombinant CBHII extract from $W$. anomalus 54-A (rCBHII extract), and (3) a 1:1 Ce-Hem:rCBHII extracts mixture. After treatment, $0.2 \pm 0.02,0.4 \pm 0.01$, and $1.25 \pm 0.1 \mathrm{~g} \mathrm{~L}^{-1}$ of reducing sugars were observed for Ce-Hem, rCBHII, and 1:1 Ce-Hem:rCBHII extracts, respectively. However, when reducing sugar concentration was normalized by the CBHII units present in each extract at the beginning of the experiment (Figure 5), it was observed that rCBHII extract had production of reducing sugars similar to that obtained with the Ce-Hem extract $(p>0.05)$. Noteworthy, the use of a $1: 1 \mathrm{Ce}-\mathrm{Hem}$ :rCBHII extracts mixture allowed an increase of about 5-fold, in the reducing sugars per CBHII unit, in comparison with the results obtained by using the Ce-Hem or concentrated recombinant CBHII extracts alone, suggesting a synergistic effect of the combination of these two enzymatic extracts. To understand the reasons of this synergistic effect, we measured the activity of $\beta$-glucosidase (BG) and endoglucanase (EG) in the extracts (Figure 5). Whereas BG was detected in the three evaluated extracts, EG was only detected in Ce-Hem and Ce-Hem : rCBHII extracts. Nevertheless, there was no correlation between BG and EG activity and the increase in reducing sugars observed with the Ce-Hem : rCBHII extract. In this sense, we hypothesize that the synergistic effect observed in the Ce-Hem : rCBHII treatment could be associated with the presence of other enzymes, such as lignin peroxidase, xylanase, laccase, and manganese peroxidase [29].

Chrysanthemum wastes degradation using enzymatic extracts with native or recombinant cellulases has not been 


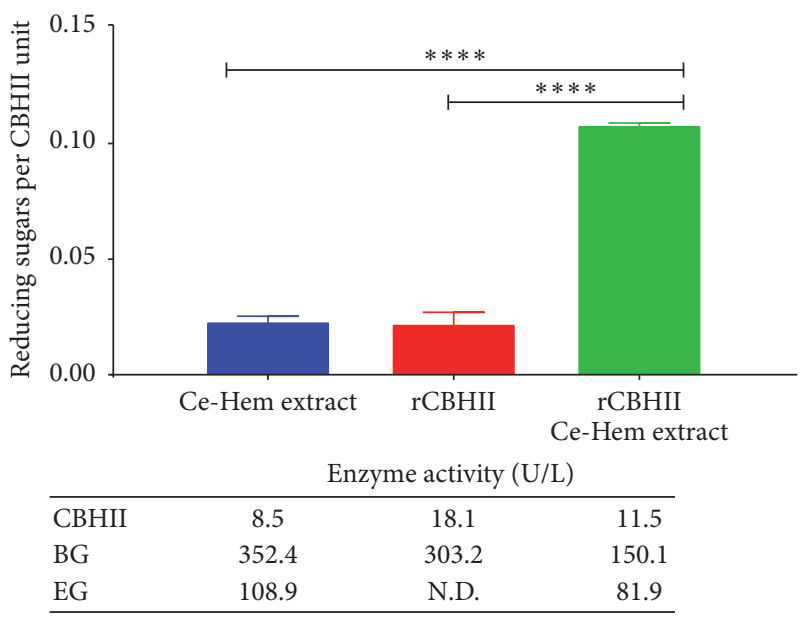

Figure 5: Chrysanthemum wastes degradation assay. The effect of recombinant CBHII on cellulose hydrolysis was evaluated by using Chrysanthemum wastes. Flasks that contained 1\% Chrysanthemum wastes were incubated for 20 days at $150 \mathrm{rpm}$ and $30^{\circ} \mathrm{C}$ with a crude culture broth from Penicillium sp. containing wild-type cellulase and hemicellulase enzymes (Ce-Hem extract), concentrated recombinant CBHII extract from $W$. anomalus 54-A (rCBHII), and a $1: 1$ $\mathrm{Ce}-\mathrm{Hem}$ : rCBHII extracts mixture. Results are reported as $\mathrm{g} \mathrm{L}^{-1}$ of reducing sugars per unit of CBHII after subtraction of the results obtained with the control cultures. $* * * *=p<0.0001$. The table shows the enzyme activities of CBHII, $\beta$-glucosidase (BG), and endoglucanase (EG) present in the enzymatic extracts at the beginning of the assay.

previously reported. For this lignocellulosic waste, degradation with $P$. ostreatus showed a production of $9.6 \mathrm{~g} \mathrm{~L}^{-1}$ of reducing sugars [18]. The higher production of reducing sugars using $P$. ostreatus could be associated with the production of several lignocellulolytic enzymes by $P$. ostreatus such as laccases (up to 6 isoforms), manganese peroxidases, cellulases, and xylanases [30-32]. The presence of all these lignocellulolytic enzymes has shown an improvement in the delignification and reducing sugars production processes [29, 33]. In addition, the use of enzymatic extracts with recombinant cellulases, to degrade lignocellulosic materials, has been preceded by chemical or physical-chemical delignification treatments, such as alkaline [10] or steam [34] pretreatments. These pretreatments allowed higher reducing sugar levels than those reported in the present study (between 1.2 and $2.0 \mathrm{~g} \mathrm{~L}^{-1}$ ), showing the importance of lignin degradation to increase biomass digestibility [29]. Nevertheless, these results showed that an enzymatic extract of $W$. anomalus 54-A carrying a recombinant $T$. reesei $\mathrm{CBHII}$ allows production of reducing sugars similar to that of a crude extract from cellulolytic fungi, showing the potential of W. anomalus 54-A as a host to produce recombinant cellulases.

In conclusion, we reported the production of the recombinant $T$. reesei $\mathrm{CBHII}$ in $W$. anomalus $54-\mathrm{A}$ strains. The results showed production of recombinant CBHII in $W$. anomalus 54-A, with enzyme activity levels of up to $14.5 \mathrm{U} \mathrm{L}^{-1}$. Recombinant CBHII showed optimum $\mathrm{pH}$ and temperature reaction of 5.0-6.0 \pm 0.2 and $40^{\circ} \mathrm{C}$, respectively, which were similar to those reported for other recombinant T. reesei CBHII enzymes. $\mathrm{Km}$ of this recombinant CBHII was between the ranges of values reported for other CBHII enzymes. The results showed that an enzymatic extract of $W$. anomalus 54-A carrying the recombinant $T$. reesei $\mathrm{CBHII}$ allows production of reducing sugars similar to that of a crude extract from cellulolytic fungi, showing the potential of $W$. anomalus 54-A as a host to produce recombinant cellulases. Noteworthily, this is the first report on the use of W. anomalus as a host to produce heterologous proteins. Further studies should be focused on the consolidation of $W$. anomalus as a platform to produce recombinant proteins such as the design of specific expression vectors and the generation of auxotrophic strains.

\section{Additional Points}

One-Sentence Summary. This work represents the first report on the use of the yeast Wickerhamomyces anomalus as a host to produce heterologous proteins.

\section{Conflicts of Interest}

The authors declare that they have no conflicts of interest.

\section{Acknowledgments}

The authors thank Dr. Pilar Melendez from Pharmacy Department at Universidad Nacional de Colombia for the kind donation of the $W$. anomalus A-54 strain. Dennis J. DíazRincón and Alexander Rodríguez-López received young researcher and doctoral scholarship, respectively, from Pontificia Universidad Javeriana. Angela Espejo-Mojica received a doctoral scholarship from the Administrative Department of Science, Technology and Innovation, Colciencias. The authors thank Nicolas Contreras for his assistance during performing experiments. This work was supported by Pontificia Universidad Javeriana [Grant ID 00005578, Producción de Etanol Mediante la Degradación de Residuos de Crisantemo Empleando Enzimas Recombinantes Producidas en Saccharomyces cerevisiae].

\section{References}

[1] L. Cuervo, J. L. Folch, and R. E. Quiroz, "Lignocelulosa como fuente de azúcares para la producción de etanol," BioTecnología, vol. 13, pp. 11-25, 2009.

[2] V. Juturu and J. C. Wu, "Microbial cellulases: Engineering, production and applications," Renewable and Sustainable Energy Reviews, vol. 33, pp. 188-203, 2014.

[3] R. C. Kuhad, R. Gupta, and A. Singh, "Microbial cellulases and their industrial applications," Enzyme Research, vol. 2011, Article ID 280696, 11 pages, 2011.

[4] J. Zhou, Y.-H. Wang, J. Chu, L.-Z. Luo, Y.-P. Zhuang, and S.-L. Zhang, "Optimization of cellulase mixture for efficient hydrolysis of steam-exploded corn stover by statistically designed experiments," Bioresource Technology, vol. 100, no. 2, pp. 819$825,2009$.

[5] M. Tanghe, B. Danneels, A. Camattari et al., "Recombinant Expression of Trichoderma reesei Cel61A in Pichia pastoris: 
Optimizing Yield and N-terminal Processing," Molecular Biotechnology, vol. 57, no. 11-12, pp. 1010-1017, 2015.

[6] S. H. Petersen, W. H. Van Zyl, and I. S. Pretorius, "Development of a polysaccharide degrading strain of Saccharomyces cerevisiae," Biotechnology Techniques, vol. 12, no. 8, pp. 615-619, 1998.

[7] J. H. D. Van Zyl, R. Den Haan, and W. H. Van Zyl, "Overexpression of native Saccharomyces cerevisiae exocytic SNARE genes increased heterologous cellulase secretion," Applied Microbiology and Biotechnology, vol. 98, no. 12, pp. 5567-5578, 2014.

[8] M. Bailey, M. Siika-aho, A. Valkeajarvi, and M. Penttila, "Hydrolytic properties of two cellulases of Trichoderma reesei expressed in yeast," Biotechnology and Applied Biochemistry, vol. 17, no. 1, pp. 65-76, 1993.

[9] M. E. Penttilä, L. André, P. Lehtovaara, M. Bailey, T. T. Teeri, and J. K. C. Knowles, "Efficient secretion of two fungal cellobiohydrolases by Saccharomyces cerevisiae," Gene, vol. 63, no. 1, pp. 103-112, 1988.

[10] H. Fang and L. Xia, "Heterologous expression and production ofTrichoderma reesei cellobiohydrolase II in Pichia pastoris and the application in the enzymatic hydrolysis of corn stover and rice straw," Biomass and Bioenergy, vol. 78, pp. 99-109, 2015.

[11] N. Boonvitthya, S. Bozonnet, V. Burapatana, M. J. O’Donohue, and W. Chulalaksananukul, "Comparison of the heterologous expression of trichoderma reesei endoglucanase II and cellobiohydrolase II in the yeasts pichia pastoris and yarrowia lipolytica," Molecular Biotechnology, vol. 54, no. 2, pp. 158-169, 2013.

[12] A. L. Demain and P. Vaishnav, "Production of recombinant proteins by microbes and higher organisms," Biotechnology Advances, vol. 27, no. 3, pp. 297-306, 2009.

[13] J. L. Corchero, B. Gasser, D. Resina et al., "Unconventional microbial systems for the cost-efficient production of highquality protein therapeutics," Biotechnology Advances, vol. 31, no. 2, pp. 140-153, 2013.

[14] V. Passoth, M. Olstorpe, and J. Schnürer, "Past, present and future research directions with Pichia anomala," Antonie van Leeuwenhoek, International Journal of General and Molecular Microbiology, vol. 99, no. 1, pp. 121-125, 2011.

[15] L. De Vuyst, H. Harth, S. Van Kerrebroeck, and F. Leroy, "Yeast diversity of sourdoughs and associated metabolic properties and functionalities," International Journal of Food Microbiology, vol. 239, pp. 26-34, 2016.

[16] T. N. Petersen, S. Brunak, G. Von Heijne, and H. Nielsen, "SignalP 4.0: discriminating signal peptides from transmembrane regions," Nature Methods, vol. 8, no. 10, pp. 785-786, 2011.

[17] G. L. Miller, "Use of dinitrosalicylic acid reagent for determination of reducing sugar," Analytical Chemistry, vol. 31, no. 3, pp. 426-428, 1959.

[18] B. Quevedo-Hidalgo, P. C. Narvaéz-Rincón, A. M. PedrozaRodríguez, and M. E. Velásquez-Lozano, "Degradation of chrysanthemum (dendranthema grandiflora) wastes by pleurotus ostreatus for the production of reducing sugars," Biotechnology and Bioprocess Engineering, vol. 17, no. 5, pp. 1103-1112, 2012.

[19] B. Quevedo-Hidalgo, F. Monsalve-Marín, P. C. NarváezRincón, A. M. Pedroza-Rodríguez, and M. E. VelásquezLozano, "Ethanol production by Saccharomyces cerevisiae using lignocellulosic hydrolysate from Chrysanthemum waste degradation," World Journal of Microbiology and Biotechnology, vol. 29, no. 3, pp. 459-466, 2013.
[20] N. Ali, Z. Ting, H. Li et al., "Heterogeneous Expression and Functional Characterization of Cellulose-Degrading Enzymes from Aspergillus niger for Enzymatic Hydrolysis of Alkali Pretreated Bamboo Biomass," Molecular Biotechnology, vol. 57, no. 9, pp. 859-867, 2015.

[21] C. P. Kurtzman, "Phylogeny of the ascomycetous yeasts and the renaming of Pichia anomala to Wickerhamomyces anomalus," Antonie van Leeuwenhoek, International Journal of General and Molecular Microbiology, vol. 99, no. 1, pp. 13-23, 2011.

[22] K. M. Lee and N. A. DaSilva, "Evaluation of the Saccharomyces cerevisiae $\mathrm{ADH} 2$ promoter for protein synthesis," Yeast, vol. 22, no. 6, pp. 431-440, 2005.

[23] V. L. Price, W. E. Taylor, W. Clevenger, M. Worthington, and E. T. Young, "Expression of heterologous proteins in Saccharomyces cerevisiae using the ADH2 promoter," Methods in Enzymology, vol. 185, pp. 308-318, 1990.

[24] T. T. Teeri, P. Lehtovaara, S. Kauppinen, I. Salovuori, and J. Knowles, "Homologous domains in Trichoderma reesei cellulolytic enzymes: Gene sequence and expression of cellobiohydrolase II," Gene, vol. 51, no. 1, pp. 43-52, 1987.

[25] B. Laukens, C. De Visscher, and N. Callewaert, "Engineering yeast for producing human glycoproteins: Where are we now?" Future Microbiology, vol. 10, no. 1, pp. 21-34, 2015.

[26] M. Klein, S. Swinnen, J. M. Thevelein, and E. Nevoigt, “Glycerol metabolism and transport in yeast and fungi: established knowledge and ambiguities," Environmental Microbiology, vol. 19, no. 3, pp. 878-893, 2017.

[27] D. Kennes, H. N. Abubackar, M. Diaz, M. C. Veiga, and C. Kennes, "Bioethanol production from biomass: Carbohydrate vs syngas fermentation," Journal of Chemical Technology and Biotechnology, vol. 91, no. 2, pp. 304-317, 2016.

[28] A. Chang, I. Schomburg, S. Placzek et al., "BRENDA in 2015: Exciting developments in its 25th year of existence," Nucleic Acids Research, vol. 43, no. 1, pp. D439-D446, 2015.

[29] O. Sánchez, R. Sierra, and C. J. Alméciga-Díaz, "Delignification Process of Agro-Industrial Wastes an Alternative to Obtain Fermentable Carbohydrates for Producing Fuel," in Alternative Fuel, M. Manzanera, Ed., InTech, pp. 111-154, Rijeka, 2011.

[30] R. Castanera, G. Pérez, A. Omarini et al., "Transcriptional and enzymatic profiling of pleurotus ostreatus laccase genes in submerged and solid-state fermentation cultures," Applied and Environmental Microbiology, vol. 78, no. 11, pp. 4037-4045, 2012.

[31] J. M. R. da Luz, M. D. Nunes, S. A. Paes, D. P. Torres, M. D. C. S. da Silva, and M. C. M. Kasuya, "Lignocellulolytic enzyme production of Pleurotus ostreatus growth in agroindustrial wastes," Brazilian Journal of Microbiology, vol. 43, no. 4, pp. 1508-1515, 2012.

[32] O. S. Isikhuemhen and N. A. Mikiashvilli, "Lignocellulolytic enzyme activity, substrate utilization, and mushroom yield by Pleurotus ostreatus cultivated on substrate containing anaerobic digester solids," Journal of Industrial Microbiology and Biotechnology, vol. 36, no. 11, pp. 1353-1362, 2009.

[33] J. Plácido and S. Capareda, "Ligninolytic enzymes: a biotechnological alternative for bioethanol production," Bioresources and Bioprocessing, vol. 2, no. 23, pp. 1-12, 2015.

[34] S. P. Das, A. Ghosh, A. Gupta, A. Goyal, and D. Das, "Lignocellulosic fermentation of wild grass employing recombinant hydrolytic enzymes and fermentative microbes with effective bioethanol recovery," BioMed Research International, vol. 2013, Article ID 386063, 2013. 

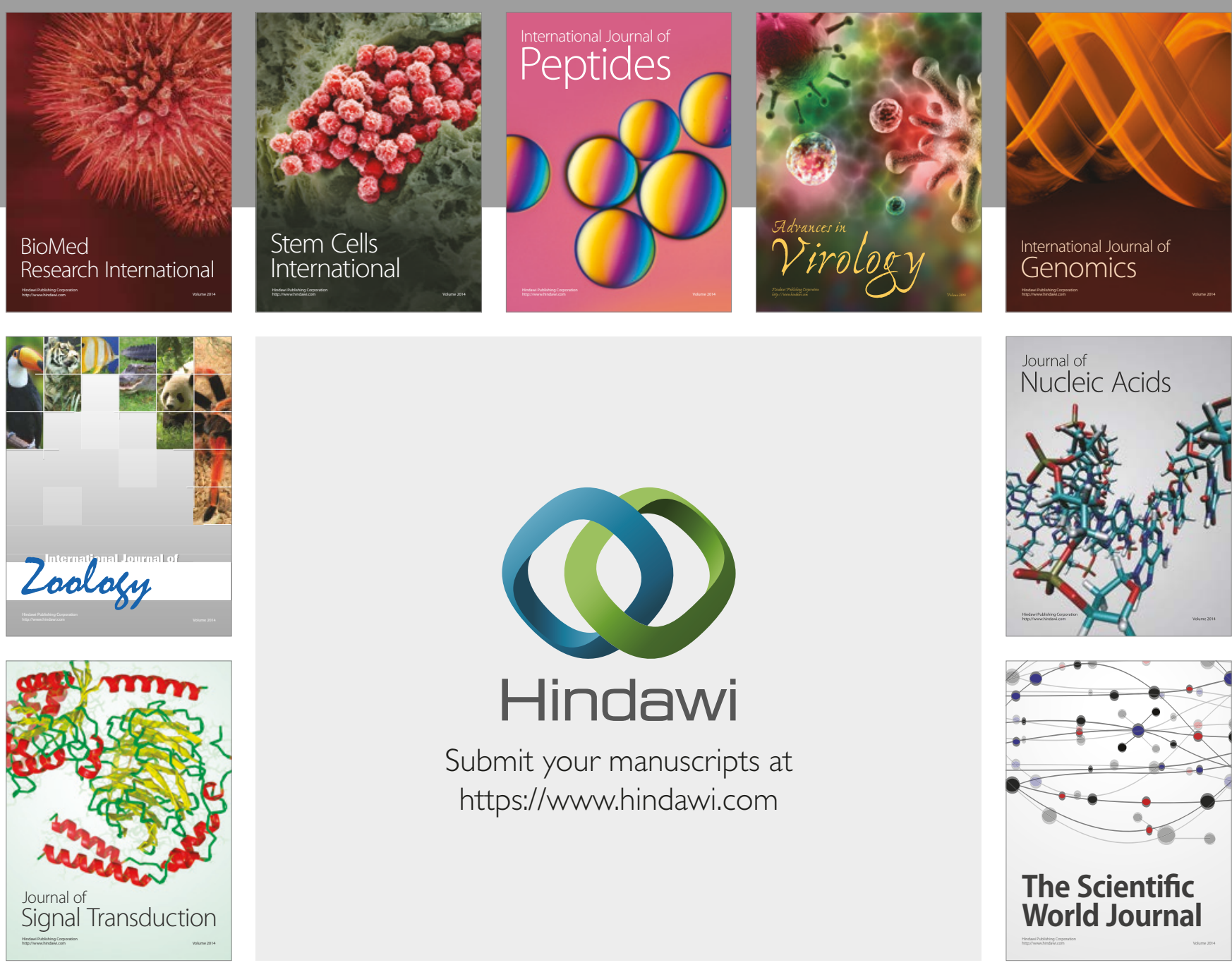

Submit your manuscripts at

https://www.hindawi.com
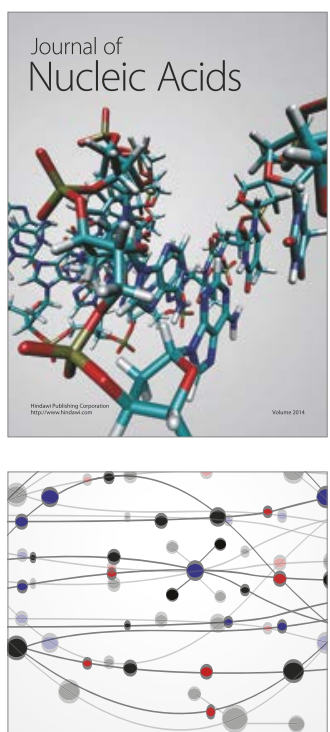

The Scientific World Journal

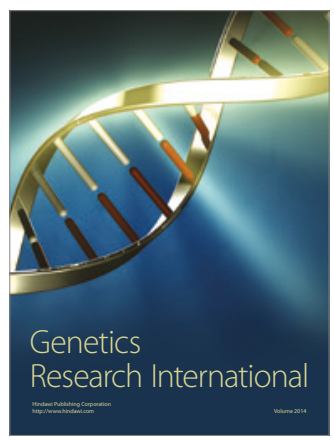

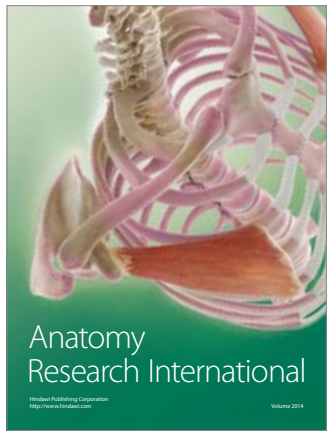

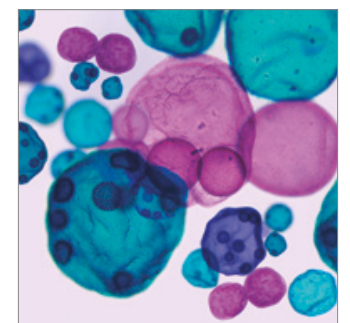

International Journal of Microbiology
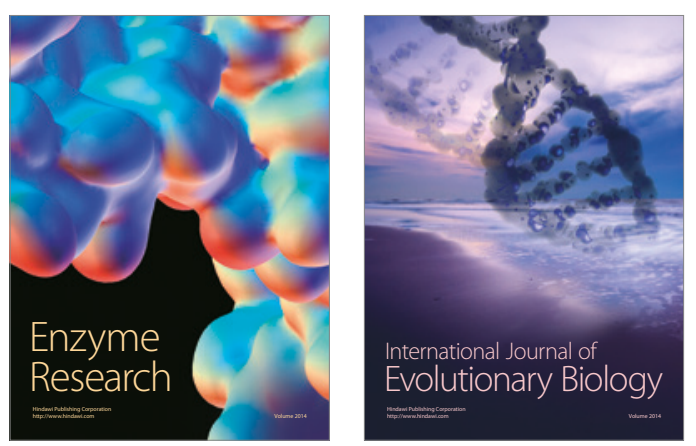
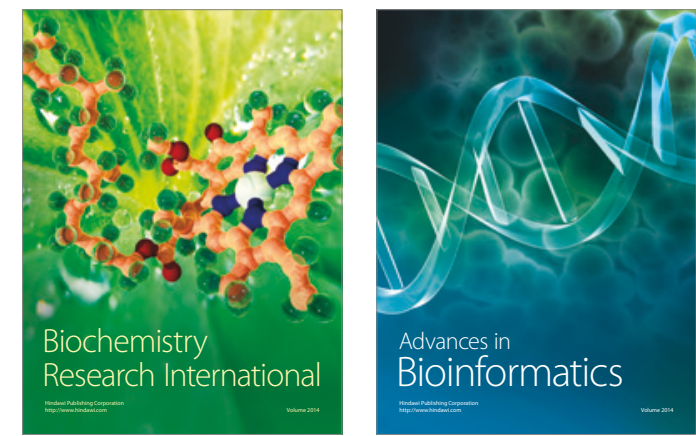

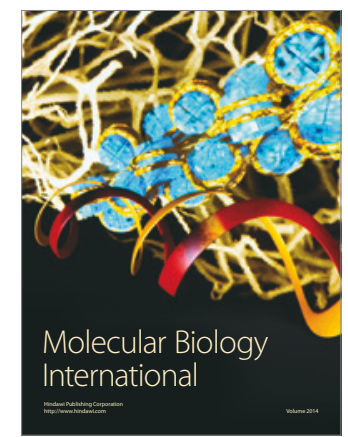

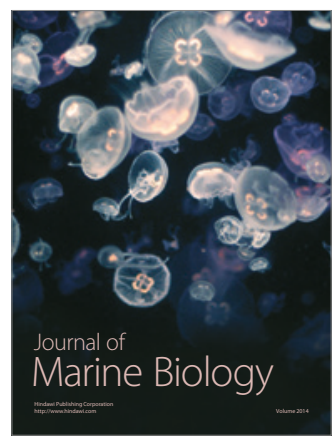

